\title{
ON THE SCALES OF THE SPRING SALMON.
}

\author{
By C. McL.ean Fraser, Ph.D., Curator Pacific Coast Biological Station, Departure \\ Bay, British Columbia.
}

A paper on "Growth of the spring salmon" was read at the San Francisco meeting of the Pacific Fisheries Society, August 9-11, 1915, and appears in the proceedings of that meeting. A more detailed analysis of the data on which it was based and of data obtained from new material, is here presented.

The spring salmon (Oncorhynchus tschawytscha), otherwise known as the king, tyee, chinook, or quinnat, has been the most highly favoured for investigation of all the Pacific Coast species, and much good work has been done by Rutter, Gilbert, Chamberlain, and others, largely in connection with the United States Bureau of Fisheries. By means of long-continued observations, these men and their associates have been able to put on record many facts concerning the life-history of this valuable species. In this instance, some additions, obtained by the methods recently made use of in the North Sea investigations by Hjort, Dahl, and others, are offered. McMurrich and Gilbert have included the spring salmon in the species of which the age at maturity was discussed. Incidentally, that phase of the study of scales will be considered in connection with an investigation into the rate of growth, and its bearing on the life-history of the species.

The validity of the conclusions drawn from scale study depends largely on the interpretation of the "annual rings" or "winter checks." The propriety of introducing these terms has been seriously questioned by many who have failed to see such a significance in the portions of the scale under discussion. It seemed useless to go on with scale investigation unless some definite assurance could be obtained on this point. Two species, the Pacific herring and the spring salmon, may be obtained throughout the zear in the strait of Georgia, and hence these offered a basis for information. For reasons given later, the spring salmon was chosen and an investigation that began with the idea of personally settling the "winter check" question was enlarged to include other points in connection with the life-history.

\section{THE "WINTER CHECK."}

There is no disputing the fact that in the seales of some species of fish there are areas arranged concentrically, having a different appearance to the remainder of the scale. As they are concentric they may be appropriately called "rings." Under normal conditions of growth is there one of these rings formed on each scale during each year?

Einar Lea has investigated the matter in the case of the North Sea herring, and the argument he advances is a convincing one. ${ }^{1}$ By examining herring of the same year class, caught at short intervals over a considerable period, and from these getting measurements, he concluded that the somewhat transparent ring on the scale was formed during the period from December to March, the main growth of the scale or almost the entire growth, taking place during the other months. Though this ring is annual and is produced during the winter months, his evidence shows that the rate of growth is not primarily dependent on temperature.

${ }^{1}$ A study of the growth of herrings, Publ. de Circonstance, No. 61, Conseil Perm. Inter. pour l'Explor. de la Mer, 1911.

$38 a-2 \frac{1}{2}$ 
In the scale of the herring the characteristic markings, the elevated lines, run transversely across the scale; the winter check, concentrically placed, consequently crosses the regular lines at right angles laterally but runs nearly parallel with them medially. The rings are narrow and, since they are formed at the margin of the scale, it is impossible to tell when a ring begins or when it ends, with any degree of accuracy. Hence Lea had to resort to many measurements and calculations of growth. Because of this difficulty it is possible to get scales more satisfactory than the herring scales, and it is for this reason that the scales of the spring salmon have been taken in preference.

The characteristic elevated lines on the salmon scales are quite different from those on the herring scales. The arrangement is concentric around a more or less nearly circular nucleus, so that each of these lines form rings, or rather partial rings, as few of them are completed on the exposed portion of the scale. These rings are wide apart in certain areas, while in other areas at regular intervals they are quite close together. Corresponding to the transparent rings on the herring scale, therefore, there are narrow bands of closely applied rings. The term "annual ringo" must have a somewhat different significance in the two cases, although the cause may be similar, but it is possible that "winter check" can be applied equally well to each. The close band is so much wider than the ring in the herring scale that it is easily possible in the majority of cases to decide when it begins or ends.

As previously stated, spring salmon are to be obtained in the strait of Georgia at all times of the year, and hence, in all probability, some of them at least remain in the strait during the whole period of their existence in salt water. The fall, winter; and spring, 1914-15, were particularly favourable for getting material. As there was so little cold or stormy weather the handline fishermen were able to go out almost every day, seldom doing so without some return for their labours. $A$ number of men from Departure Bay fished throughout the season, and it was a simple matter to obtain data at short intervals. The majority of the fish examined were caught by Mr. E. Webber, who made special effort to have the series as complete as possible. The temperature data were obtained from daily surface readings at the station, and occasional readings at depth.

The appearance of a year's growth on a salmon scale has a much closer approximation to that of the growth in a twig of wood than that of the herring scale. The area of distant rings corresponds to the loose texture of the spring and summer growth in the twig. The rings get closer during the fall until there is a compact band corresponding to the winter ring in the wood. It was to the time that the compact band made its appearance that special attention was paid.

In the scales of fish caught in the summer time, with rare exceptions, there is always a wide area outside of any compact band, hence it was evident that this close band could not be formed at that time of the year. During the fall a certain amount of retardation was indicated since the lines near the margin were closer together. Later the beginning of the more compact band was evident in some scales, then in all, and still later the outer limit was reached and the distant lines appeared once more.

In all scales of salmon caught from January 6 to March 17 there was indication of the check in growth at the margin. On the other hand, with but few exceptions, no scales obtained after April 22 and before November 27 had indication of retardation at the margin. From March 17 to April 22 and from November 27 to January 5 some show retardation at the margin while others do not, this being true even in specimens caught on the same day. The period of check here corresponds so exactly with that reported by Lea for the herring that it can scarcely be considered a mere coincidence. As the time corresponds in general to the winter season, the term "winter check" is not inappropriate. 


\section{SESSIONAL PAPER No. 38a}

In order to compare the temperatures of the water during the "winter check" period with those before and after, a table of surface temperatures to cover the months from October to May, inclusive, is given, as well as a table showing temperatures at depth, taken at intervals during that period. The surface temperatures were taken at the station landing float, and the deeper temperatures about four miles out, east of Five Finger island, that being the nearest point at which water over 100 fathoms could be reached. The surface readings were taken by a Negretti and Zambra deepsea thermometer or one standardized against it and the deep-water temperatures with a Richter deep-sea thermometer in connection with a Pettersen-Nansen water-bottle.

TABLE I.

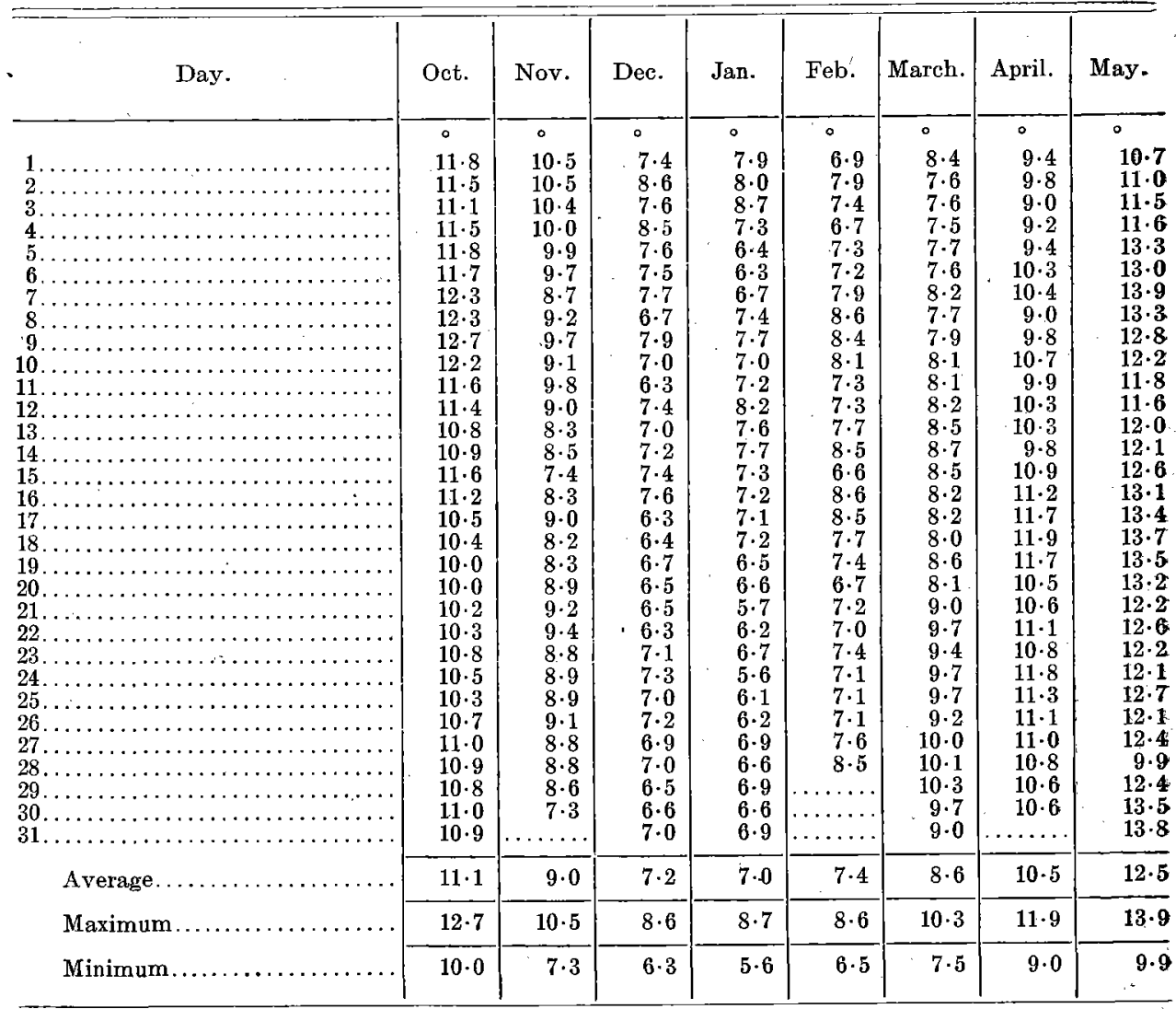

TABLE II.

$\ldots$
$\ldots$

The readings are all Centigrade readings. 
It will be seen from the tables that during the three months, December, January and February, the average temperatures differ little, but are lower than during the other months, while the greater portion of the retardation of growth takes place during January, February, and March. November, during which there was no evidence of check except during the last few days, was colder, on the average, than March, and had a lower minimum. October was almost as warm as April, and yet retardation is evident on occasion almost to the end of April. There are only 4.1 degrees of difference between the average of October and January, and only 2 degrees between the average for November and January. There may be that much difference between the temperature at the surface and at a depth of 5 fathoms (in table II there is a difference of 3.6 degrees shown thus for September 9 ), and 5 fathoms would certainly not be too great depth for a salmon to reach. Doubtless there is a maximum, an optimum and a minimum temperature for growth, but it is scarcely probable that if the optimum is reached at 13 or 14 degrees, 7 degrees would be at or near the minimum, and if it were, 8.6 degrees, the average for March, should be far enough away from that minimum to show a definite increase of growth instead of showing a continuation of the minimum.

If the check is due to the lowering temperature, one would naturally expect that the change should take place in all of the fish of the same species in the same region at or near the same time, and yet some have close rings beginning on November 27, while others have little or no sign of them on January 5; some have got over the check on March 17, while others retain it on April 22. Between these dates in the two cases there is a period of time equal to almost half of the time during which all show retardation. Again, if the check is due to the lowering temperature, all in the same vicinity should have checks of nearly the same width, but instead there is a great variation from ore or two rings to six or seven. The variation occurs in the individuals in one year class as much as in any of the others, and after the first year is over the individuals that migrate as fry are affected in the same way as those that migrate as yearlings.

Nothing shows better the entire lack of relation between rate of growth and temperature than the graphs for each for the entire year. In making a graph for the growth rate, the average percentage of the total growth for the year was taken for each half-month. As the new growth for the year starts about April 1, that is taken for the basis of calculation. In the graph for water temperature (surface) the average for each half-month was taken also. The graph showing the percentage of the year's growth completed during each half-month is also given.

The curves for growth rate and temperature are so unlike that they are scarcely comparable. The greatest growth rate is in May, the highest temperature in August, by which time the growth rate has become materially reduced. The growth curve has a sharp ascent from the first of April until the middle of May and a very gradual descent for the rest of the year; the temperature curve has a gradual ascent from January until August and' a gradual descent for the rest of the year. Half of the total growth for the year takes place during April, May and June, before the temperature has nearly reached its greatest height. During the next two and a half months another quarter is added, leaving but a quarter for the next six and a half months, but by the middle of September the temperature has decreased very little.

It may be remarked here that there is no indication of a total cessation of growth during January, February, and March, such as Lea says occurs in the North Sea herring. The growth is very much retarded but does not cease entirely. The width of the winter bands shows this to be true.

Taking all of these points into consideration, it can scarcely be maintained that temperature has any very definite primary effect on rate of growth.

Tables somewhat similar to those given for temperature could be given for density or salinity during the same period, but as they cover ground so similar it does not appear to be necessary. Suffice it to say that there seems to be just as little direct relation between salinity (as far as the limits in the waters of the strait of Georgia are concerned) and growth rate, as there is between temperature and growth rate. 


\section{SESSIONAL PAPER No. 38a}

With temperature and salinity eliminated as primary factors, the main emphasis must fall on the only other known variable that could have direct bearing on the growth of fish, viz., the food supply. That fish do not differ from other animals in which growth is accelerated by regular, suitable feeding, is shown by the success that attends the feeding of fresh-water fish in ponds, lakes, and streams. On the other hand fish, like other animals, cannot maintain normal growth if food is lacking or is insufficient in quantity to keep the various processes active. Existence may be continued for some time under such conditions, but it must be at the expense of the nourishment and energy stored up in the body. While that is being drawn upon, growth must be retarded or stopped altogether, and the weight may be considerably reduced.

The scale, like any other organ of the body, must be affected as the body as a who'e is affected, hence the variation in the food supply, even without any other important factors, could account for the difference in the rate of growth.

In fishes like the salmon, where a portion of the life is spent in the fresh water and the remainder in salt water, there is a great disparity of growth during the two periods. The richness of the marine flauna as food supply, as compared with the fresh-water fauna, makes a decided difference in favour of the former. A difference in salinity, however, complicates matters as far as evidence goes in this case. A better illustration is afforded by the difference in the rate of growth of a trout, e.g., the cut-throat, in a small pond where food is scarce and in a lake where food is abundant or where there is a wider area over which to search for it.

The variation in the food supply would seem to account appropriately for the variation in rate of growth but, unfortunately, in the case of the spring salmon, the application is not self-evident. In the spring and summer, minute crustacea and a great variety of larvæ are abundant, hence such fish as the herring that feed on this should thrive better at that time of the year. The spring salmon takes this food also, but evidently eats many fish as well. Here comes the difficulty. To judge from the stomach contents, one might say that the salmon, by preference, feeds on the herring and the herring is abundant in the strait throughout the year. They are much more in evidence during the winter months, as the schools can readily be located near shore. During February and March they remain for long periods in the same locality, in the spawning season. Some of the salmon follow the herring into shallow water since a few individuals are caught in the herring nets, and I have seen them swimming around in a school of herring not far from shore. It may be that these are stragglers while the larger numbers remain in the deeper water where the herring congregate in the summer time.

An entirely different explanation is possible. The spring salmon may prefer crustaceans, as the sockeye and the coho seem to do, taking fish only when the crustacean supply runs short. Their presence with the herring schools may be due to the fact that they, like the herring, are feeding on copepods. There is some basis for such conclusion, for spring salmon caught in the neighbourhood of herring schools have been found to contain decapods, schizopods, amphipods, and copepods. At such time I have even found annelids of the Nereis type in their stomachs, the only evidence that I have seen that they are ever bottom-feeders after they leave the fresh water. Fishermen with spoon bait often catch many salmon right in the herring schools, while herring bait at such a time is useless. If crustaceans make up the main part of the food supply, then they would fare better in spring and early summer when the pelagic crustacea are so numerous. In the winter time they take to the herring in the extremity of hunger, as being the chief food available, enough to keep them alive but not enough for ample nourishment for growth equivalent to the summer growth.

If retardation of growth in the scale is due to the lack of suitable food, an explanation is readily available for the extra checks that appear between the regular winter checks, or at the margin in fish caught during the summer. Tocal conditions 
may become such, even in the summer, that a fish cannot get a good food supply for some time, and the growth is checked. That there are not more of these checks goes to show what an abundant and well-distributed fauna there must be in the sea. Fish must be subject to periods of ill health, as all animals are, and during such times growth may be seriously retarded. This would account for the small amount of growth sometimes found between two successive winter checks.

Regenerated scales show that fish are subject to injury. As on the regenerated scales, only those rings corresponding to those formed afterwards on the normal scales appear, leaving the central portion of the scale blank. The time of the injury is thus indicated. If the injury is a serious one the normal scales on the fish may show a check on account of the retardation of growth due to the drain on the system in recovering from the injury. These checks may or may not decrease the total amount of growth for the year. In some cases it does noticeably, but in others the later growth seems to have been accelerated so as to fully make up for the lost time.

At first such extra checks may cause considerable confusion in scale reading, but after the normal scale becomes familiar, such checks, with rare exceptions, may readily be distinguished from the regular winter checks.

\section{RATE OF GROWTH.}

Since data as to length and weight of the fish from which the scales for this investigation had been recorded, these scales became available for a study of rate of growth. Since that time other material has been added. Some of this additional material was obtained from the Departure Bay fishermen, and hence is comparable to the previous material; some was obtained from the cannery at Nanaimo, some from a cannery at New Westminster (these were caught in the Fraser river), some from the Vancouver fish companies (from the Skeena and Campbell rivers), some from the cannery at Uchucklesit, Barkley sound, and a small but interesting collection from Mr. R. B. Heacock, Seabright, California. To those in charge in all these cases my thanks are due.

The lot is rather a composite one and, for some purposes, a large number from one locality taken at nearly the same time would give better results, but for other purposes, as this material contains data from specimens of all ages taken at all times of the year, from widely different localities, it is especially suitable.

In studying the rate of growth of the spring salmon it must be recognized, in the first place, that there are two types to be considered. Most observers have realized that some salmon migrate from the fresh water to the sea as fry, when they are four or five months hatched, while others remain in the fresh water throughout the first year and go down early in the second year as yearlings or fingerlings. The whole scale theory must fail if there are not two types of scales to corresoond, but it does not. The most casual observer could not fail to notice that the central portion of the scale may differ materially from the corresponding portion of the scale of another individual. There is no doubt that Gilbert's interpretation of this central portion of the scale in the two types of this species is correct.

The individual that migrates as fry has no scales when it reaches the salt water, and consequently there can be no record on the scale of life in fresh water. The scale starts to develop soon after migration, the growth is rapid, and although the late start is a big handicap, the growth in the remainder of the year is slightly greater, on the average, than that of the whole second year. There is this difference, however, the fish in its first year does not seem to be able to stand adverse conditions as well as the older fish. They may not be able to partake of as great variety of food. In consequence, the distance between the rings on the scale at times start to narrow earlier so that the summer growth gradually passes into the winter growth without giving the appearance of a distinct winter check. The chango from the winter 
SESSIONAL PAPER No. 38a

check to the next summer's growth is as abrupt as in older fish. The fry are about 1.5 inch long when they migrate, and the average length at the end of the year is about 10 inches. (Here as elsewhere in this paper the caudal fin rays are not included when the length is measured.) Some measurements, given in inches, will give some indication of the rate of growth: August 18, 5.0 (2), 5.2, 5.5 (2), 6.0, 6.5, 7.5; November 6, 10.0; December 4, 8.7; December 26, 9.7; January 28, 10.0; February 11, 10.2; March 3, 10.7; March 6, 10.2; March 11, 8.8; Aprl 3, 8.8; April 6, 11.4, 8.7; April 8, 11.6; April 13, 10.4; April 14, 10.2. After this date the rapid growth had started in all the specimens examined. At this time the fish is about a year old, or slightly more, and weighs about half a pound. In the measurements given later the first year is taken to be the period to the end of the first winter check.

Concerning the later growth it is not necessary to say very much. Broad summer bands are followed in succession by narrow winter bands. In normal individuals the limit of variation is not so very great, but naturally it increases with the age of the fish. At the end of the second year the average length of the fish examined was 20.5 inches, and the weight somewhat over 4 pounds. At the end of the third year the length was 28.5 inches, and the weight 14 pounds. At the end of the fourth year the length was about 33 inches, and the weight 22 pounds. No specimens obtained had completed the fifth year.

The fry that remains in fresh water during the first year starts to develop the scale about the same time as the one that goes to sea, but as the fish in fresh water grows very slowly; the scale grows slowly also, and the rings, even in the summer time, are quite close together. In the winter they come almost together and are cften incomplete or broken. The winter check can be distinguished more readily in the majority of specimens, by the narrow area of broken lines than by judging the distance between the lines. The fish is still under 4 inches in length, and hence does not compare at all favourably with the one that spent its first year in the sea. Tsually the migration to the sea is made early in the spring, so that the growth in salt water is indicated immediately following the winter check. In some instances, though, there is indication of a small amount of fresh-water growih outside of the winter check before the growth in salt water commences, but it never reaches an extent similar to that sometimes found in the coho. About one-third of the specimens examined showed evidence of this growth. It would seem then that a large majority -two-thirds of the whole number in this group-migrate early in the spring, in March or early in April, and the remainder follow not so very long after, so that by tue middle of May, or even earlier, the last stragglers must have disappeared from the fresh water.

After the seaward migration the growth in this type is entirely comparable to that in the other. At the end of the second year the average length is nearly 14 inches, and the weight slightly over a pound; at the end of the third year the length is over 23 inches and the weight 6 pounds; at the end of the fourth year the length is 30 inches and the weight 16 pounds. Sixth year specimens were lacking in this type also.

In making a more detailed analysis and comparison, the following data were obtained. Of 306 fish over one year old examined, 199 or 65 per cent of the whole number had migrated as fry. Of these, 83 were in the second year, 43 in the third, 59 in the fourth, and 14 in the fifth year. Of the 107 that stayed in the fresh water a year, 10 were in the second year, 18 in the third year, 44 in the fourth, and 35 in the fifth. The growth of each fish in each year has been calculated and the average for each year taken. The following table was made out for the purpose of comparison. 
7 GEORGE $V$, A. 1917.

TABLE OF GROWTH.

"Sea Trpe."

3rd.

5th.

Average

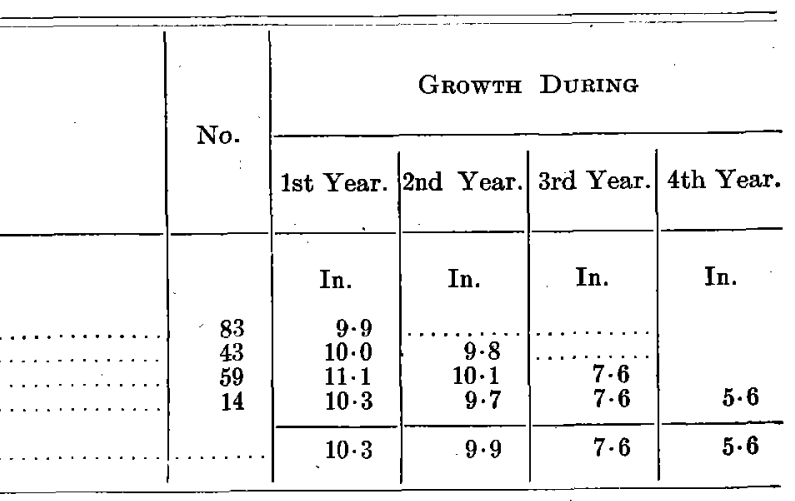

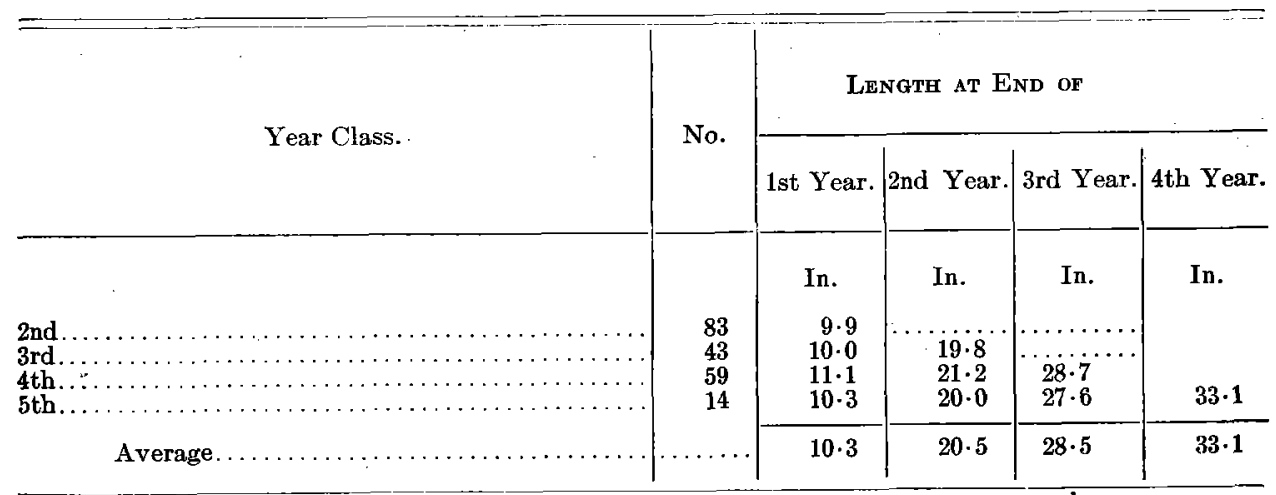

"Stream Type."

Year Class.
$\ldots$


“Stream Type"-Concluded.

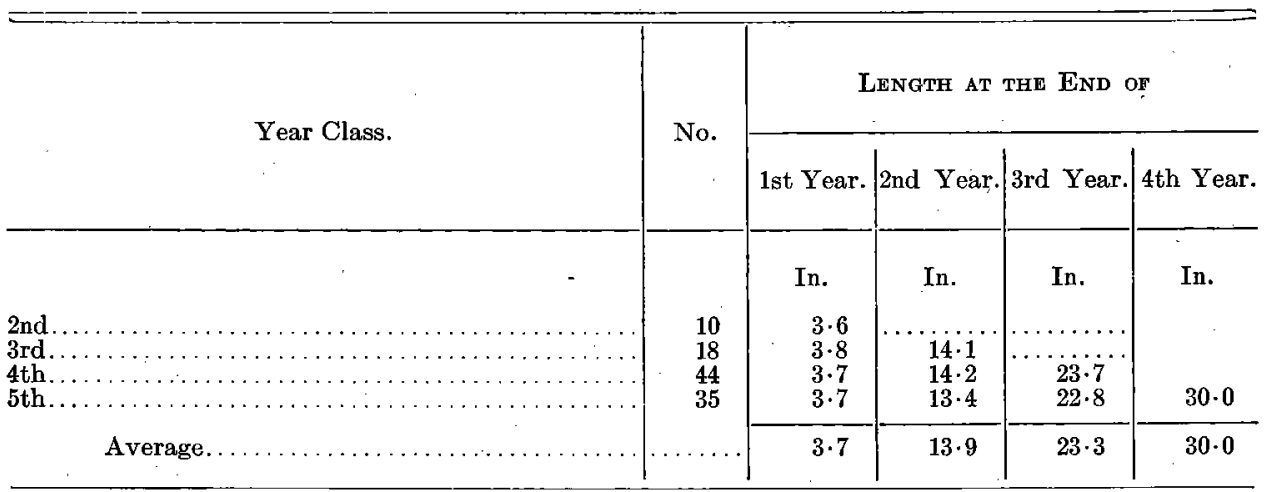

Of the mature grilse only four were obtained, all of the "sea type," in their third year. The average for them was: Growth, first year, 11.1; second year, 10.7; length at end of first year, 11.1; at end of the second year, 21.8; when caught in June, $26 \cdot 0$.

In the previous paper on "Growth of spring salmon," 2 inches was taken as the average length when the scale starts to develop. It has been found that this was too high for the average, 1.5 inch being much nearer the length. In these calculations, therefore, 1.5 inch has been taken from the total length of the fish in each case and the remainder divided in the same proportion as a line drawn from the margin of the nucleus to the margin of the scale, would be by the outside limits of the various winter checks. To the first year value thus obtained, 1.5 inch is added to get the length of the fish at the end of the first year. In making the calculation in this way there is no "phenomenon of apparent change in growth-rate" such as is shown in the various herring investigation tables of Hjort, Dahl, and others, making the strained explanations by Rosa Lee (Publications de Circonstance, No. 63, Conseil Perm. Int. prur l'Expl. de la Mer, 1912) and of Einar Lea (Ibid., No. 66, 1913) appear necessary.

When the number examined was divided up between the two types and among the different classes, the number in any one group was not large enough to make it worth while making graphs, but some points concerning each might be mentioned.

Taking the "sea type" first, the growth for the first year varies from 7.1 to 12.7 inches, but very few are less than 8.7. The number 9.3 has the greatest number of individuals, but several others have nearly as great. In the second-year growth there are some cases abnormally small, 6.2, 6.4, 6.7, 7.2. The majority fall between 8.6 and 12.2 , with 10.0 and 11.1 the most numerous. The length at the end of the second year shows much the same variety as the second-year's growth. There are low ones, $14.7,15.8,16.4$, and 16.7, and high ones, $24.1,24 \cdot 2$, and $24 \cdot 5$, but nearly all come between 17.5 and 23.5 . The growth in the third year shows much variation between the extremes of 3.8 and 4.5 on the one hand, and 11.5 on the other, but the greater number come between 7.0 and 8.5. This makes a great variation in length at the end of the third year, all the way from 24.2 to 31.8 , the majority falling between 27.5 and 29.5 . In the fourth-year growth there is less variation, 4.2 and 6.7 being the extremes, but at the end of the year the length varies from 29.9 to 37.9 , with one abnormally low at 28.3. Those taken in the fifth year were taken at different times and a fair comparison can scarcely be made, but with the exception of the abnormal one just mentioned, which became only 30.5 , there was a variation from 33.0 to 40.0 , with an average of 35.8 . 
7 GEORGE V, A. 1917

In the fish of the "stream type," since the growth in the first year, after the alevin stage is passed, is small, there is little variation as given in inches, for the length at the end of the first year. The extremes are 3.2 and 4.1 , with the greatest number at 3.6 and the next at 3.9. In the second-year growth there is a range from 7.7 to 12.8 , but nearly all are between 8.4 and 12.0 . The length at the end of the second year varies from 11.4 to 16.5 , but nearly all are between 12.1 and 15.9 . In the third-year growth there are three exceptionally low, 5.1, 5.8, and $6 \cdot 4$, and apart from this there is a variation from 6.9 to 12.5 , the majority being between 8.3 and 11:0. At the end of the third year, with the exception of six abnormal ones, one of which is only 16.9 , the length varies from 21.1 to 26.9 , and is fairly well distributed between these extremes. In the fourth year the increase is small in two cases, 5.0 and 5.3 and high in two others, 8.9 and 9.8. The remainder falls between 5.7 and 8.4 , with the majority between 7.0 and 8.0. The length at the end of the fourth year varies from 25.8 to 34.0 , but nearly all fall between 29.5 and 31.5 . Of those caught in the fifth year, all but three were obtained on June 22 . The average length when caught was 32.4 , with a variation from 28.5 to 36.5 .

For material from such a variety of sources, the growth values for each year show very little difference in the different classes. The differences are greater in fishes of the "sea type," since, as the spring salmon do not all spawn at the same time of the year, some of the fry must be more or less than a year old at the end of the first winter check. With the fish of the "stream type" the growth of the first year is so small that all start on much the same basis at the beginning of the second spring.

There is one point quite prominent in both types, and hence worth considering. 'Those fish that have matured in their fourth year have higher average growths throughout than those that do not mature until the fifth year. From this it would seem that the larger fish of a year-class spawn in the fourth year and the smaller ones of the class spawn in the fifth year. If this is true, we should expect that those that mature as grilse in the third year should be the largest of the year class. Too few were examined to justify any definite statement, but it may be said that these do not show that that might not be so. One would need to get several fish of the same year-class for three years in succession before the conclusion would be sufficiently definite.

The comparison would be more complete if six-year or even seven-year fish (Gilbert records one fish in its seventh year) could have been included. Gilbert says very little about the six and seven-year fish that he has seen. The sixth-year scale that he figures is of the "stream type" it would be interesting to know if all the others were, as well as the nature of the seventh-year fish. The data from such would have a decided bearing on the question here discussed, but in this region, at any rate, they would not appear to be sufficiently numerous to be a factor in the commercial phase of the question.

As quite a complete series of fish up to 35 inches was obtained, and as the weight of these over 5 inches was recorded, it is possible to get a satisfactory graph to show the ratio of weight to length. The curve is as regular as one could expect from the degree of accuracy of weights and measurements. There were only ten fish in the collection over 35 inches, and these show much irregularity in weight. There were: four 35.5 , varying from 21 to 28.5 pounds; one $36 \cdot 0$, weighing 28 ; one $36.5,25$; Ine 37.5 , 39 ; one 38,28 ; one $39,35.5$; and one 40.0 weighing 36.5 pounds.

The sex was not determined in the fish obtained from New Westminster and Vancouver, hence the data are not sufficient to say definitely if there was much difference in weight between the males and the females of the same length, as this lot contained a large proportion of the mature specimens. In those where the sex was determined there was no material difference. 


\section{SESSIONAL PAPER No. 38a}

In comparing the salmon of the "sea type" with those of the "stream type" throughout, the former shows to good advantage. At the end of the first year, it has a length 6.6 inches greater than the other, and a somewhat similar superiority is maintained throughout. At the end of the second year three is still 6.6 inches difference and a difference of over 3 pounds in weight, as the small fish weighs very little over a pound while the larger weighs over 4 . At the end of the third year the difference in length is 5.2 inches and the difference in weight, 7.5 pounds. At the end of the fourth year, the difference in length is 3.1 inches and the difference in weight, 6.5 pounds. At the time they are caught in June and July, if they are in the fourth year, the average length of the "sea type" is 31.7 inches, and of the "stream type" 26.3 inches, a difference of 5.4 inches, and a corresponding difference in weight of 7.5 pounds; if they are caught in their fifth year, there is an average difference in length of 3.4 inches, and in weight of 6.5 pounds. As in this collection 65 per cent are fish of the "sea type," it would seem to be a good thing if the remainder should be encouraged to behave likewise. Hence, instead of keeping the fry of the spring salmon in retaining ponds for a year, and losing thereby many pounds of mature fish, it would be much better to give all of them every facility in getting down to the salt water and a better supply of food as soon as they can stand the change physiologically. The only offset there is comes from the fact that a larger number of fish of the "sea type" than of the "stream type" are mature in the fourth year. The latter has one year longer to grow in such cases. As it is scarcely any larger in the fifth year than the former is in the fourth, there is no special advantage even here. If five years instead of four are taken to produce a certain size of fish, there must be (1) loss of 25 per cent here as well.

It must be distinctly understood that these remarks apply to the spring salmon only, and to the spring salmon as I have found it. It does not necessarily apply to any other species of Pacific salmon. That quite the opposite is true for the coho is shown in another paper being published, and it remains to be seen what is the nature of the application in other species.

\section{SUMMARY.}

The growth of the scale in the spring salmon is a good indication of the growth of the fish. Annual bands of growth appear on the scale, each consisting of a wide portion with the lines on it somewhat distant, and a narrow portion with the lines closer together. The narrow band may be called the "winter check" appropriately, because, although the retardation of growth is due to a lack of food rather than to a lowering of the temperature, it is produced in the winter months, January, February, snd March, with indications of it in December and April.

There are two types of scales, since some of the salmon migrate to the sea as fry and have no fresh-water record on their scales, while others migrate as yearlings or fingerlings after having a year of comparatively slow growth on the fresh water clearly indicated on the scales.

The majority of both types mature in their fourth or fifth years; probably a greater percentage of the "sea type" than of the "stream type" mature in the fourth year, but a majority of the whole number are of the "sea type." The fish that mature in the fourth year are, as a rule, among the larger of the year-class. Possibly if enough third-year grilse were examined there would be proof that they are among the largest of the year-class.

The "sea type" fish has a decided advantage throughout life, both in length and in weight, so much so that an average fish of the "stream type", mature in the fifth year, is scarcely larger than a "sea type" fish mature in the fourth year. If they are both in the same year when mature, either the fourth or fifth, there is an average difference of 6 or 7 pounds. Unless there is some other preponderating reason for 
7 GEORGE V, A. 1917

keeping spring salmon in rearing ponds for a year, it is decidedly unwise to do so, as, taking it either in size or in time, there must be a handicap of at least 20 or 25 per cent in favour of the "sea-type" fish.

\section{EXPLANATION OF PLATES.}

Plate I.

Fia. 1. Scale of spring salmon in third year showing summer growth at the margin, caught June 6.

“ 2. Scale of spring salmon near the end of the third year showing winter check at margin, caught February 16.

“ 3. Scale of spring salmon in second year showing winter check starting at margin, caught November 27.

“4. Scale of spring salmon in second year with winter check just starting at margin, caught January 5 .

Plate II.

* 5. Scale of spring salmon at the beginning of the fourth year with summer growth starting at the margin, caught March 17.

“ 6. Scale of spring salmon at the beginning of the third year with summer growth well begun at the margin, caught April 5.

4 7. Scale of spring salmon at the beginning of the third year with no summer gromth showing at the margin, caught April 13.

“ 8. Scale of spring salmon at the beginning of the third year with no summer growth showing at the margin, caught April 22.

“9. Scale of spring salmon in the third year, regenerated in the fall of the second year and showing the second winter check.

Plate III.

“ 10. Scale of spring salmon in third year with n check showing at the margin during summer growth, caught July 26.

" 11. Centre of scale of spring salmon of "stream type" in fourth year, in which migration took place immediately after winter check.

\section{Plate IV.}

“ 12. Centre of scale of spring salmon of "stream type" in. second year, showing fresh water growth after the first winter check.

" 13. Centre of scale of spring salmon of "sea type" in second year.

GRAPHS.

“ 14. A curve to show percentage for each half month of the total growth for the year. A curve to show at the end of each half month, the percentage of the whole growth of the year attained. A curve (interrupted) showing the annual variation of the temperature of the surface water.

" 15. A curve showing ratio of weight to length. 
Plate I.

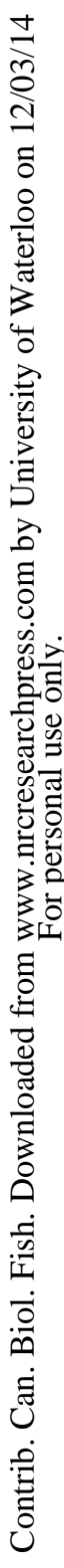

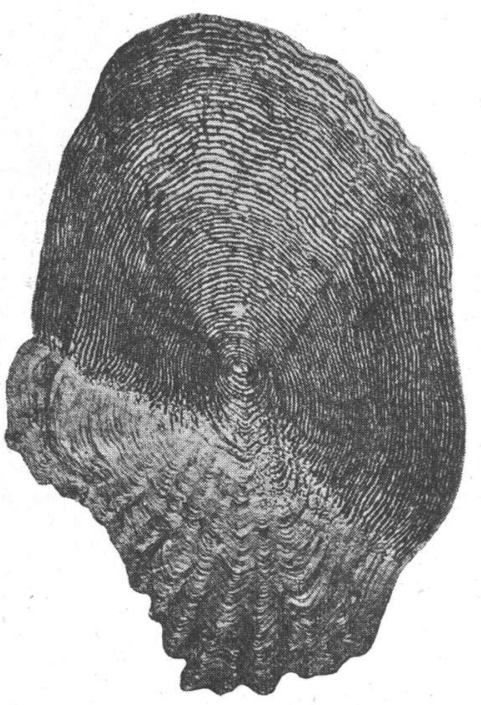

1
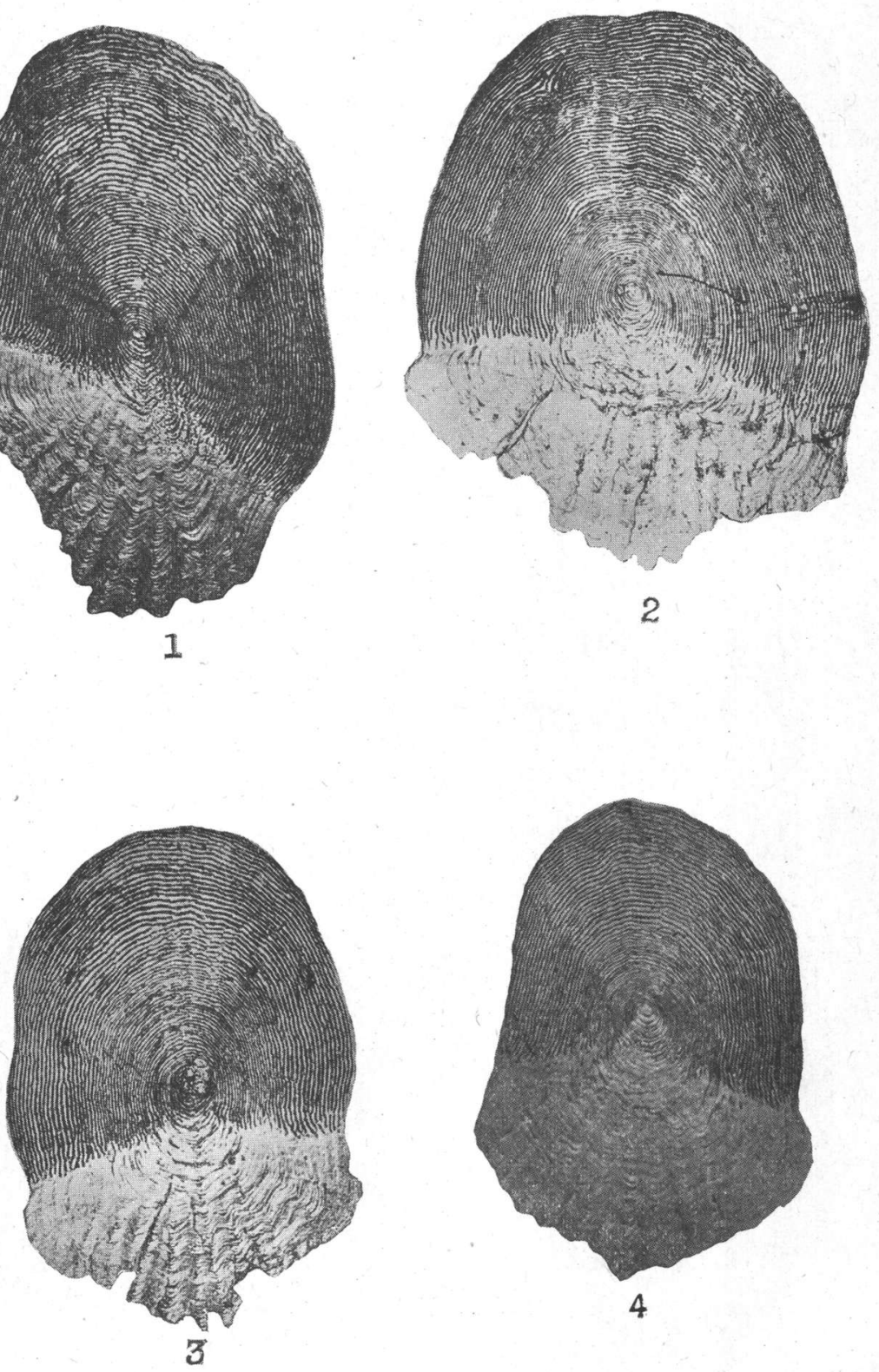

Spring Salmon. 
Plate ir.

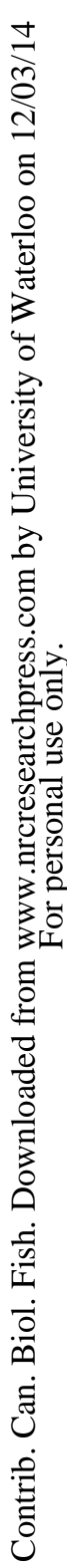
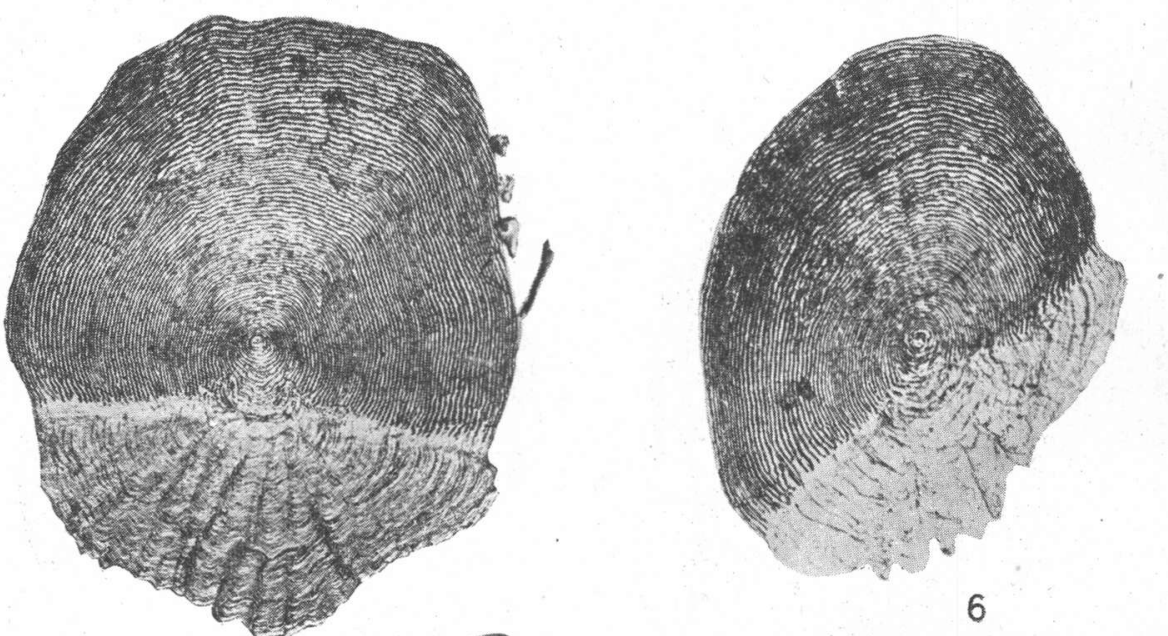

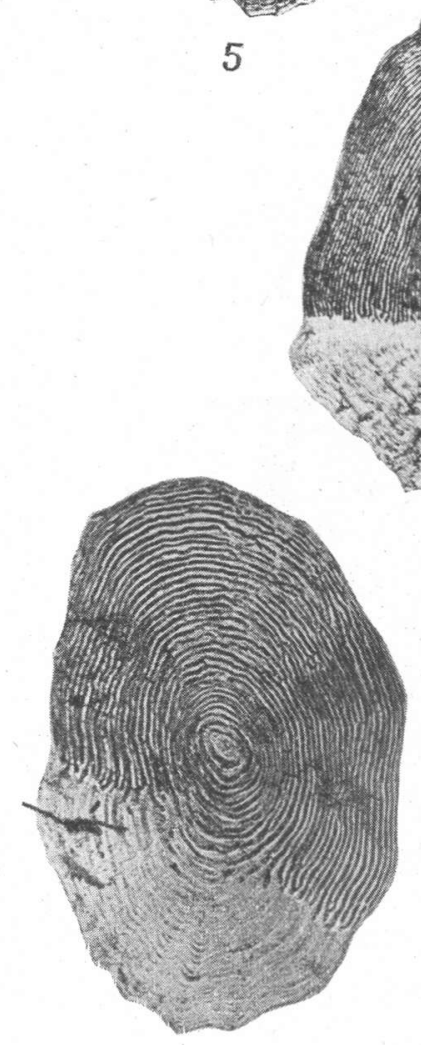

8

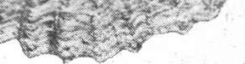

7

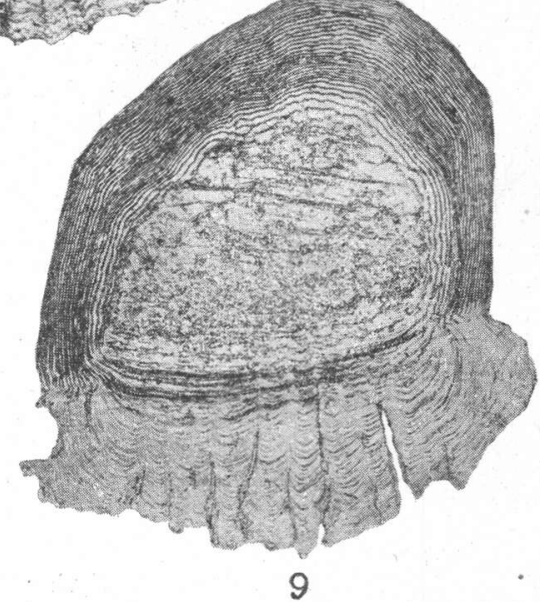

9

Spring Salmon. 
Plate III.
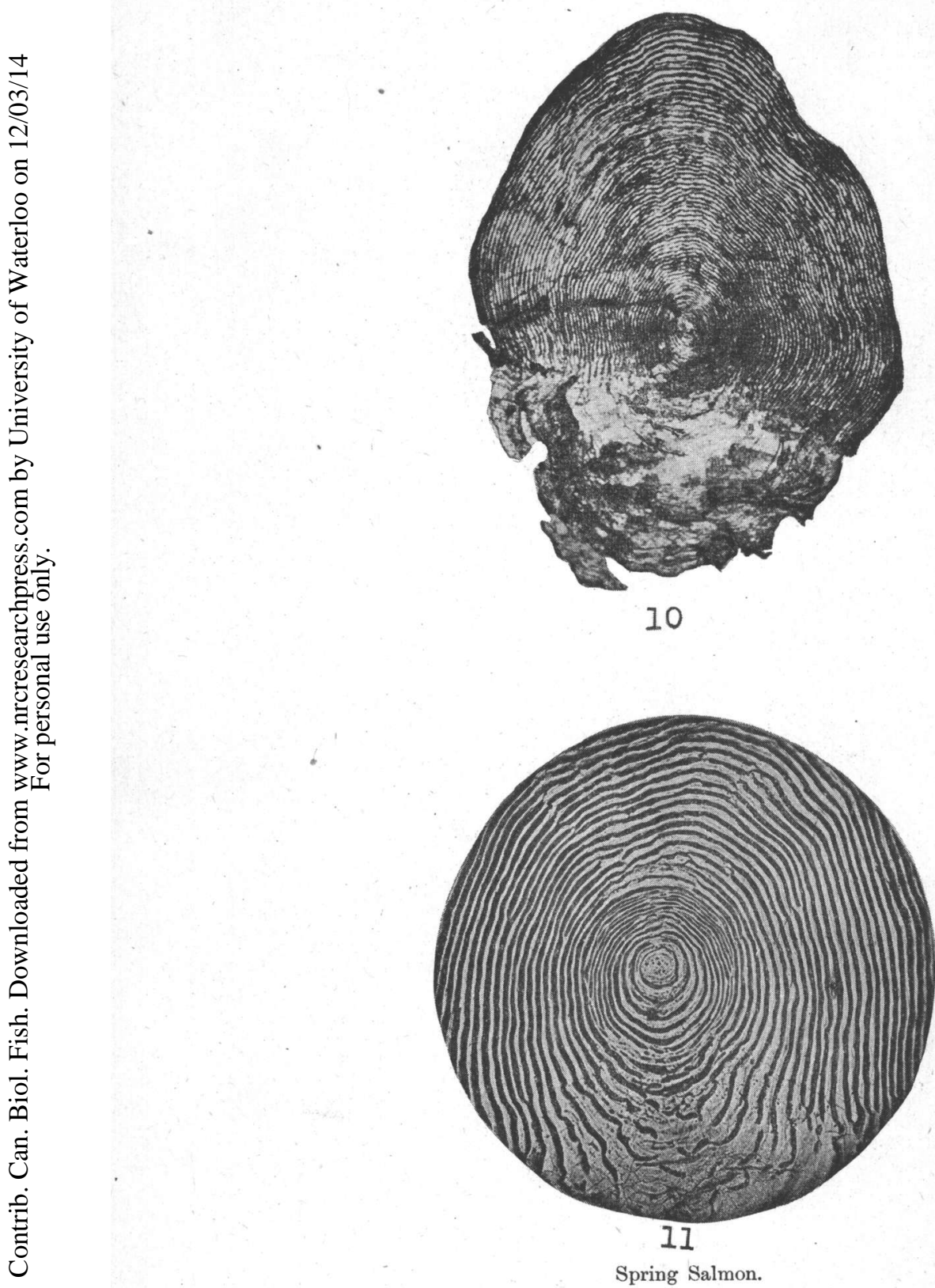

Spring Salmon. 
Fig. 14.

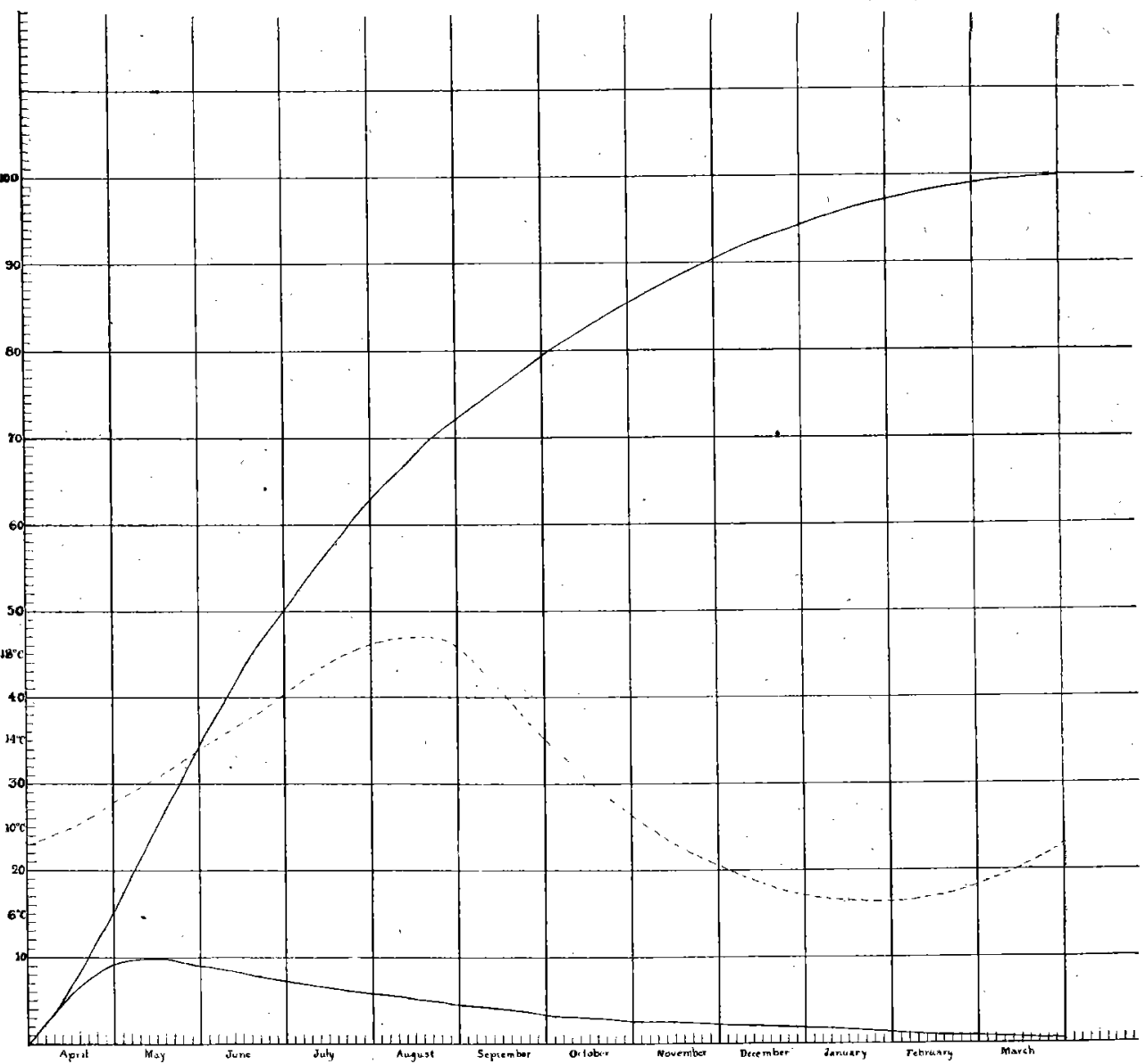

Spring Salnon.

A curve to show percentage for each half month of the total growth for the year. A curve to show at the end of each half month, the percentage of the whole growth of the year attained. A curve (interrupted) showing the annual variation of the temperature of the surface water. 


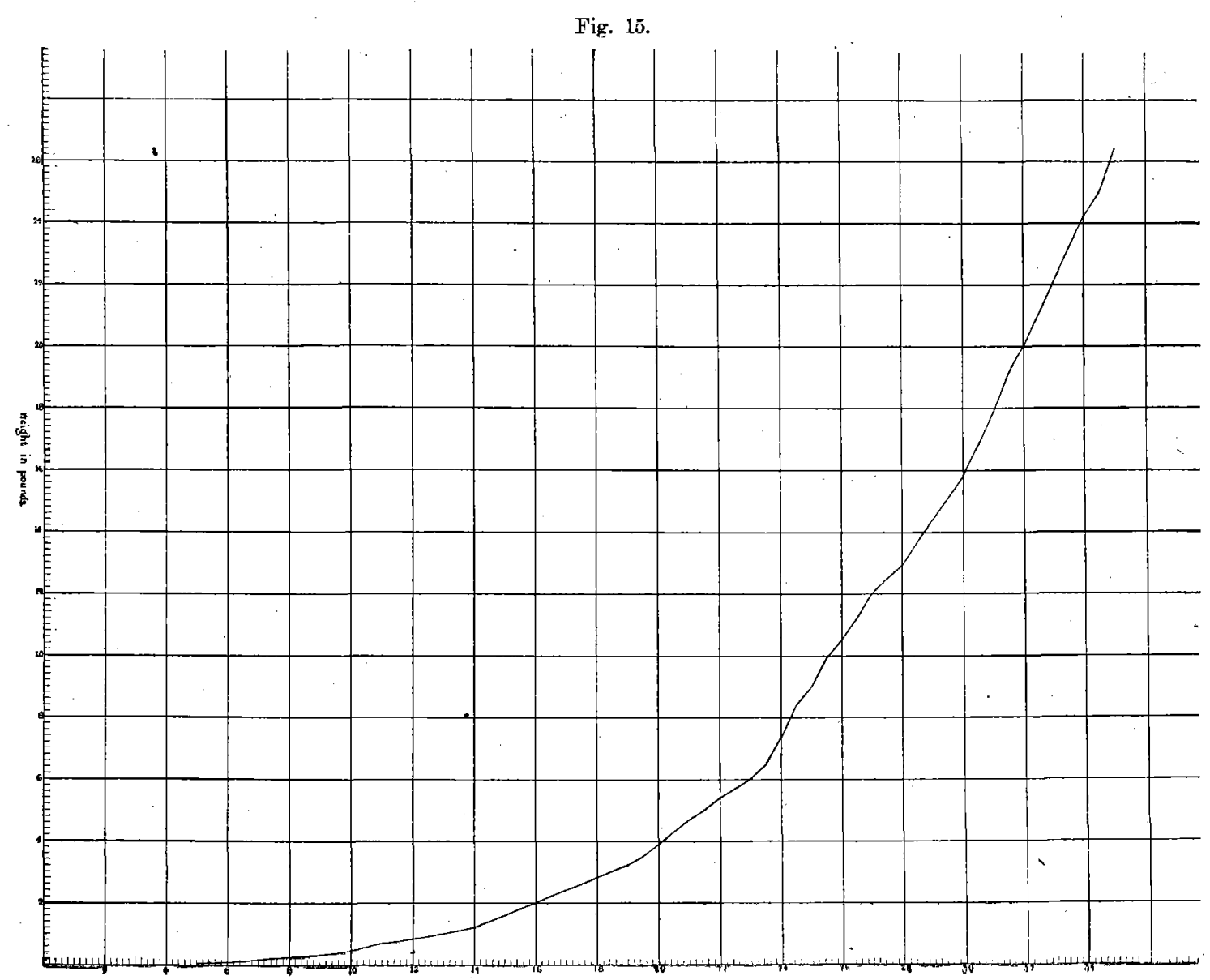

Spring Salmon. A curve showing ratio of weight to lengtb. 